\title{
GERAÇÃO DE RESÍDUOS DE CONSTRUÇÃO CIVIL NO MUNICÍPIO DE BEBEDOURO - SP
}

\author{
Gustavo Henrique Vital Gonçalves (Universidade Federal de São Carlos) \\ guvital1@hotmail.com \\ José da Costa Marques Neto (Universidade Federal de São Carlos) joseneto@ufscar.br \\ Leonardo Brian Gonçalves da Rocha (Centro Universitário Unifafibe) 11.brian@ hotmail.com
}

\section{RESUMO}

O número de novas construções e reformas no Brasil vem aumentando nos últimos anos, tendo em vista que esse crescimento resulta também nos altos índices de resíduos gerados e em seguida depositados de forma incorreta no meio ambiente. Com isso, faz-se necessário um gerenciamento mais adequado do RCC e o primeiro passo para isso é quantificá-lo e caracterizá-lo. Sendo assim, o objetivo deste trabalho foi o de realizar o levantamento quantitativo e qualitativo de resíduos de construção civil gerados no município de Bebedouro - SP, entre os anos de 2017 e 2018. Para tanto, foi realizado o levantamento de dados através de pesquisa documental juntamente à prefeitura do município, a análise dos resíduos e a coleta, separação e a pesagem. O resultado mostrou que há uma média diária de 41,80 ton/dia de resíduos gerados no município e o material com maior volume encontrado foi o concreto $(31,88 \%)$, em seguida a argamassa/reboco $(31,32 \%)$. Conclui-se, portanto, que, conforme a Resolução CONAMA $n^{\circ}$ 307/02, 94,78\% desses resíduos encontrados referem-se a resíduos da classe A, possíveis de serem reciclados ou reutilizados em forma de agregados.

Palavras-chave: Gestão de Resíduos. RCC. Meio Ambiente.

\section{INTRODUÇÃO}

Embora a indústria da construção civil tenha intensificado as suas atividades no Brasil, contribuindo com o desenvolvimento social e econômico do país, o setor é conhecido como um grande consumidor de recursos naturais e por sua geração de resíduos. Com isso, surgiram as buscas por melhorias na administração dos resíduos de construção e da preservação do meio ambiente, necessitando de estudos tanto no cenário ambiental quanto no econômico, (YEHEYIS et al., 2013).

A PNRS - Política Nacional de Resíduos Sólidos, instituída pela Lei $\mathrm{n}^{\circ} 12.305$ (BRASIL, 2010), classifica as origens dos resíduos de construção civil visando a diminuição 
do volume de resíduos gerados no país, ampliando o cenário da reciclagem, incluindo socialmente catadores de lixo como ajuda na gestão e repartição dos resíduos e na realização da extinção dos lixões brasileiros (ALVES; SANTOS, 2018).

Nas construções realizadas nos municípios brasileiros, pode-se observar uma grande quantidade de RCC gerados, frisando os altos índices de materiais sendo desperdiçados pelos colaboradores e as indústrias (OLIVEIRA; MENDES, 2018).

Atualmente no Brasil, um dos principais problemas para os governantes municipais é a geração de resíduos e, logo em seguida, a sua disposição final. Desse modo, o aumento no preço da limpeza pública e a degradação do meio ambiente e das áreas de descarte se dão por meio da má gestão desses resíduos. Isso faz com que os pesquisadores precisem realizar estudos sobre as alternativas mais viáveis para uma boa gestão ambiental (MARQUES NETO, 2010).

A importância dos levantamentos qualitativo e quantitativo se dá por intermédio da ação administrativa dos municípios para ter o controle e o planejamento de todas as etapas construtivas. Essas etapas incluem, além da precaução, a análise do ciclo de vida dos resíduos, a redução dos volumes produzidos, a reciclagem, a reutilização, o tratamento e a destinação final de cada um deles (MARQUES NETO, 2005).

Sendo assim, o presente trabalho tem como objetivo realizar o levantamento quantitativo da geração de Resíduos de Construção Civil (RCC) no município de Bebedouro/SP, utilizando como parâmetro as áreas licenciadas nos anos de 2017 e 2018, bem como realizar a caracterização qualitativa desses resíduos para traçar estratégias de reciclagem e destinação correta desses materiais no munícipio.

\section{REFERENCIAL TEÓRICO}

\subsection{Resíduos de construção civil}

O crescente aumento de resíduos resultantes da construção civil faz com que os resíduos de construção civil (RCC) sejam depositados irregularmente no ambiente, trazendo consigo uma série de problemas ao meio ambiente, como a contaminação das águas e solos, e a proliferação de agentes patogênicos e animais, além do aspecto visual desagradável (SILVA et al., 2015). 
Nesse contexto, a geração desses RCC está ligada diretamente com o desperdício de materiais nas construções, uma vez que desperdícios são gastos que ocorrem nas etapas construtivas associadas às perdas dos materiais. Vale ressaltar ainda que o termo desperdício vai além da concepção de perdas e prejuízos, incluindo também mão de obra, mau funcionamento de equipamentos e a compras de materiais superiores necessários (NASCIMENTO, 2014).

A Política Nacional de Resíduos Sólidos (PNRS), instituída pela lei $\mathrm{n}^{\circ}$ 12.305, específica ainda que os resíduos de construção civil são obtidos através das reformas, construções, reparos e demolições das obras, incluindo as etapas iniciais das obras resultantes da escavação e preparação dos terrenos (BRASIL, 2010).

Segundo Shingo (1996), há 7 classificações desses desperdícios, levando em conta a falha e o setor no qual foi produzido. São as chamadas 7 perdas da produção:

a) Perdas por produção elevada de determinado produto;

b) Perdas por demora de tempo;

c) Perdas por quebras ou danos dos materiais no momento do transporte;

d) Perdas no andamento do processo construtivo;

e) Perdas pelo armazenamento e estoque incorreto;

f) Perdas pelo excesso de movimentação;

g) Perdas por materiais com defeitos de fábricas.

Com o alto índice de crescimento populacional e a respectiva necessidade de moradias e infraestrutura, a quantidade de resíduos gerados nas construções civis aumenta consequentemente. Sendo assim, deu-se início ao estudo e a realização da gestão dos RCC no município. (MARQUES NETO, 2009).

\subsection{Gestão dos resíduos}

O processo de administração dos resíduos de construção civil realizado pelos municípios brasileiros não é eficiente e, por muitas vezes, fica de responsabilidade da prefeitura fazer esse processo de destinação correta dos resíduos. No entanto, as prefeituras não possuem recursos humanos especializados em planejar, executar, e gerenciar os enormes volumes de entulhos produzidos, algo que se torna um problema para os governos municipais (MARQUES NETO; SCHALCH; 2010). 
Segundo Neto e Schalch (2010), o padrão de gestão adotado nos munícipios brasileiros é o de gestão emergencial e corretiva, que se caracteriza por falta de informações dos gestores e, sendo assim, ineficiente para uma boa gestão ambiental.

A resolução CONAMA 307/2002 discorre que um Programa de Gerenciamento de Resíduos de Construção Civil (PGRCC) deverá conter as seguintes etapas:

a) Identificação e classificação dos resíduos: como exemplificado no item 2.3. Caracterizações dos resíduos;

b) Triagem: As normas e diretrizes para a instalação de área de triagem são dadas pela ABNT 15112/2014 e referem-se a um local para a segregação dos resíduos;

c) Acondicionamento: É de responsabilidade do gerador garantir que os resíduos estejam devidamente acondicionados após a sua geração nas obras até a seguinte etapa de transporte, de forma que suas condições sejam viáveis para uma possível reutilização ou reciclagem (BRASIL, 2002). Esse tipo de armazenamento deverá ser feito de acordo com as classes, tipos e destinação final dos resíduos, com o intuito de facilitar o transporte, podendo ser utilizados coletores, bombonas, big bags, baias, caçambas, entre outros modelos (MENDES; GIACCOM, 2018).

d) Transporte: A retirada dos resíduos deve ser feita por empresas autorizadas, que passam por uma avaliação para saber se está apta a prestar o serviço com qualidade. Além disso, a empresa prestadora de serviço deverá possuir uma autorização de operação. Toda a retirada dos resíduos deve obter a aprovação e a liberação por parte da equipe de sustentabilidade do empreendimento que gerou o resíduo e o preenchimento do MTR - Manifesto de Transporte de Resíduos (MENDES; GIACCOM, 2018).

e) Destinação final: Da disposição dos resíduos ao meio ambiente a PNRS (2011) em seu artigo $3^{\circ}$ define que deve ser feita a repartição dos rejeitos nos aterros de forma ordenada, observando as próprias diretrizes operacionais, a fim de preservar a saúde, a segurança pública e a minimização dos impactos ambientais.

Quando feita a coleta dos resíduos nas obras pelas empresas receptoras, estas fazem a emissão do CDR - Certificado de Destinação de Resíduos, contendo a identificação dos resíduos e da empresa, além da caracterização, da origem, da data e das assinaturas (BARROS; SOUZA, 2017). 


\subsection{Munícipio de Bebedouro - SP}

O município de Bebedouro está localizado no Estado de São Paulo (Figura 1), na latitude $20^{\circ} 56^{\prime} 58^{\prime}$ ' sul, longitude $48^{\circ} 28^{\prime} 45^{\prime}$ ' oeste e uma altitude de $573 \mathrm{~m}$, possuindo uma área de 684,4 Km² (GEOGRÁFOS, 2019).

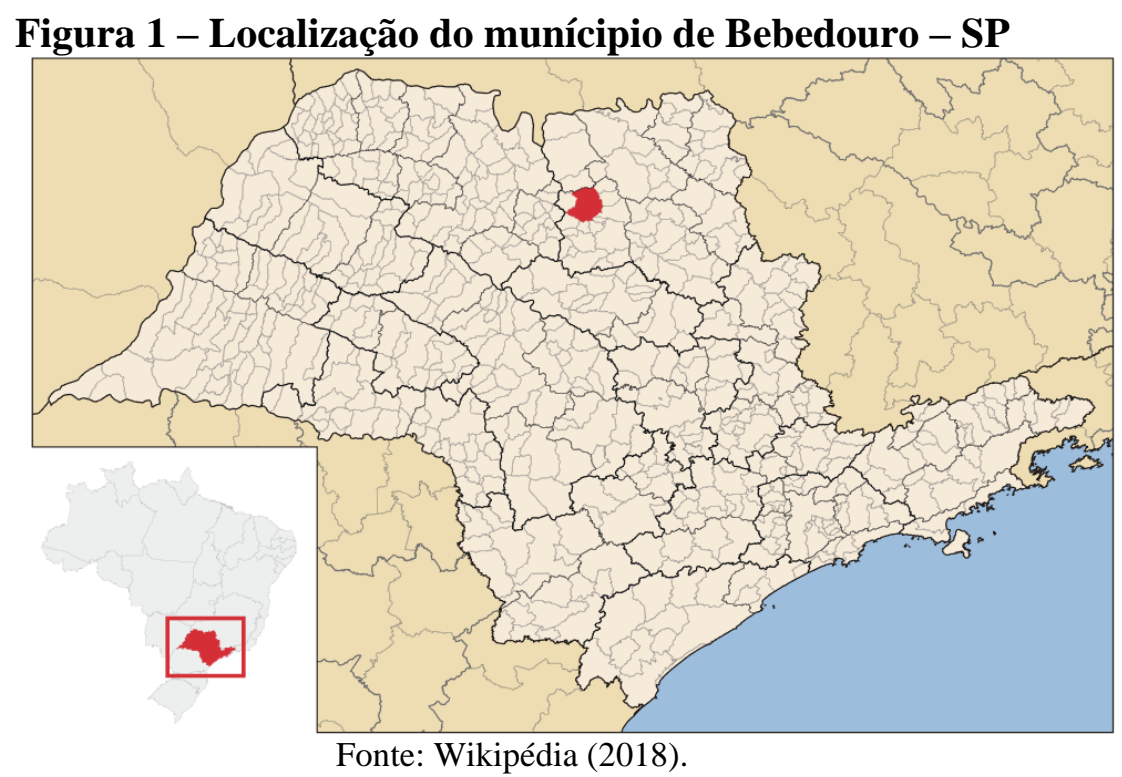

O município dispõe de uma população estimada de 77.496 habitantes, o esgotamento sanitário adequado de $96,5 \%$, arborização das vias públicas de $96,8 \%$ e a urbanização de vias públicas de 22,1\% (IBGE, 2018).

As informações sobre a gestão ambiental do município de Bebedouro estão divididas em 10 frentes de ações ambientais constadas no Banco de Dados Ambiental, sendo elas: Munícipio Sustentável - MS, Estrutura e Educação Ambiental - EEA, Conselho Ambiental CA, Biodiversidade - BIO, Gestão das Águas - GA, Qualidade do Ar - QA, Uso do Solo US, Arborização Urbana - AU, Esgoto Tratado - ET, e por fim os Resíduos Sólidos - RS, os quais se referem ao presente trabalho (IBGE, 2018).

\section{METODOLOGIA}

A metodologia aplicada neste trabalho foi proposta por Marques Neto (2005) com adaptações ao estudo de caso para realizar o levantamento qualitativo e quantitativo dos RCC gerados no município de Bebedouro - SP, sendo realizados os seguintes procedimentos: 


\subsection{Caracterização quantitativa dos $\mathrm{RCC}$ pelo cálculo de áreas licenciadas no município de Bebedouro - SP}

Para esta etapa foram utilizados levantamentos de dados por meio de pesquisa documental junto à Prefeitura Municipal de Bebedouro nos anos de 2017 e 2018. Ademais, foi utilizada a metodologia de cálculo da geração dos RCC de Bebedouro -SP pelo parâmetro das áreas licenciadas.

A metodologia consiste na triagem, na composição dos dados e no cálculo das áreas autorizadas anualmente para construções novas ou reformas junto com a Secretaria de Agricultura, Indústria, Comércio e Meio Ambiente e a Secretaria de Infraestrutura Urbana da Prefeitura Municipal de Bebedouro. Com o intuito de realizar a quantificação de massa e volume produzidos a partir dessas áreas licenciadas do município foram definidas algumas etapas a serem seguidas, tais como:

a) Levantamento mensal das áreas licenciadas no município, no período estudado;

b) Somatória dos levantamentos mensais, obtendo o valor total no período;

c) Levantamento de dados e informações sobre a geração de RCC em cinco obras, sendo elas construções novas ou reformas, com diferentes características;

d) Determinação do volume de resíduos produzidos nessas obras em relação à área;

e) Cálculo da massa total elaborado através da relação de massa/volume obtida pela massa unitária procedente da composição dos RCC.

\subsection{Caracterização qualitativa dos RCC do município de Bebedouro - SP}

A composição dos RCC constituiu uma das etapas mais importantes da análise da situação desses resíduos no município. Com base nos tipos de materiais encontrados nos RCC e de seus percentuais, é possível arquitetar estratégias de reciclagem e de controle das perdas de materiais nas construções da cidade.

Foi desenvolvida, por meio da separação e pesagem dos materiais oriundos de pelo menos três caçambas metálicas descartadas nos aterros municipais, a caracterização física desses resíduos. O método teve como roteiro:

a) Seleção de três caçambas de $3 \mathrm{~m}^{3}$ de origens diferentes;

b) Coleta de cinco amostras de 18 litros de cada caçamba;

c) Junção das cinco amostras de 18 litros em apenas uma amostra, por caçamba;

d) Divisão dos componentes encontrados nas caçambas; 
e) Medição de volume e massa;

f) Total dos resíduos das três caçambas e considerados amostra representativa da composição dos RCC;

g) Cálculo da massa unitária;

h) Cálculo percentual da composição dos materiais contidos nos RCC.

\section{RESULTADOS E DISCUSSÃO}

\subsection{Levantamento das áreas licenciadas no município de Bebedouro - SP}

A coleta dos dados foi feita juntamente à Prefeitura Municipal de Bebedouro - SP, referentes ao período de janeiro de 2017 a dezembro de 2018. A tabela 1 apresenta de forma detalhada as áreas licenciadas do período estudado, possibilitando determinar o índice da estimativa de RCC gerado no município.

Tabela 1 - Relação de alvarás concedidos pela Prefeitura do Município de Bebedouro SP

\begin{tabular}{|c|c|c|c|c|c|c|}
\hline \multicolumn{7}{|c|}{ Áreas Licenciadas } \\
\hline & & 2017 & & & 2018 & \\
\hline Mês & $\begin{array}{l}\text { Quantidade } \\
\text { de Alvarás }\end{array}$ & $\begin{array}{c}\text { Área } \\
\text { construída } \\
\left(\mathbf{m}^{2}\right)\end{array}$ & $\begin{array}{c}\text { Área } \\
\text { Reformada } \\
\left(\mathbf{m}^{2}\right)\end{array}$ & $\begin{array}{l}\text { Quantidade } \\
\text { de Alvarás }\end{array}$ & $\begin{array}{c}\text { Área } \\
\text { construída } \\
\left(\mathbf{m}^{2}\right)\end{array}$ & $\begin{array}{c}\text { Área } \\
\text { Reformada } \\
\left(\mathbf{m}^{2}\right)\end{array}$ \\
\hline Janeiro & 37 & $4.451,00$ & $2.568,32$ & 42 & $7.094,36$ & $1.152,46$ \\
\hline Fevereiro & 32 & $3.790,35$ & 706,21 & 40 & $5.073,45$ & $1.344,34$ \\
\hline Março & 43 & $5.856,79$ & 409,50 & 39 & $4.321,93$ & $1.506,97$ \\
\hline Abril & 40 & $4.162,78$ & $1.511,92$ & 37 & $3.795,01$ & 792,08 \\
\hline Maio & 44 & $3.253,23$ & $2.230,40$ & 34 & $3.079,72$ & 239,23 \\
\hline Junho & 45 & $4.374,55$ & $1.084,29$ & 36 & $5.557,75$ & 657,85 \\
\hline Julho & 54 & $4.106,30$ & 446,79 & 37 & $4.802,09$ & 253,77 \\
\hline Agosto & 49 & $7.290,45$ & 742,44 & 32 & $2.888,46$ & $1.062,30$ \\
\hline Setembro & 32 & $4.508,20$ & $2.913,45$ & 35 & $3.278,66$ & 780,39 \\
\hline Outubro & 37 & $5.420,82$ & $2.515,69$ & 38 & $7.299,64$ & 839,60 \\
\hline Novembro & 51 & $5.309,01$ & 262,62 & 27 & $18.072,88$ & 126,15 \\
\hline Dezembro & 34 & $6.047,77$ & 910,43 & 30 & $3.507,69$ & $1.554,39$ \\
\hline TOTAL & 498 & $58.571,25$ & $16.302,06$ & 427 & $68.771,64$ & $10.309,53$ \\
\hline
\end{tabular}

A quantificação dos resíduos gerados pelo parâmetro das áreas licenciadas foi realizada através do acompanhamento e da análise de duas construções e três reformas, sendo elas residenciais e comercial, distintas, dentro do período de estudo, sendo calculados os volumes produzidos por elas durante suas execuções. 
A tabela 2 apresenta os perfis das obras analisadas, incluindo a quantidade de caçambas e suas áreas.

Tabela 2 - Análise das obras estudadas no município de Bebedouro - SP

\begin{tabular}{ccccc}
$\begin{array}{c}\text { Construções } \\
\text { Analisadas }\end{array}$ & Obra & Tipo & $\begin{array}{c}\text { Caçambas } \\
\text { Retiradas }\end{array}$ & Área $\left(\mathbf{m}^{2}\right)$ \\
\hline $\mathbf{1}$ & Construção & Residencial & 16 & 349,55 \\
$\mathbf{2}$ & Construção & Residencial & 5 & 45,62 \\
$\mathbf{3}$ & Reforma & Residencial & 6 & 118,9 \\
$\mathbf{4}$ & Reforma & Residencial & 12 & 142,85 \\
$\mathbf{5}$ & Reforma & Comercial & 38 & 598,60 \\
\hline Total & - & - & 77 & $1.255,52$ \\
\hline
\end{tabular}

Para o cálculo do volume, temos a seguinte relação:

$\sum$ Área das obras $\left(m^{2}\right)=$ Årea $1+$ Årea $2+$ Área $3+$ Årea $4+$ Årea 5

$\sum$ Área das obras $\left(m^{2}\right)=349,55+45,62+118,90+142,85+598,60$

$\sum$ Área das obras $\left(m^{2}\right)=1.255,52 m^{2}$

$\sum$ Total de caçambas retiradas $=$ obra $1+$ Obra $2+$ obra $3+$ obra $4+$ obra 5

$\sum$ Total de caçambas retiradas $=16+5+6+12+38$

$\sum$ Total de caçambas retiradas $=77$

Todas as caçambas em que foi realizado o estudo e sua coleta possuem o volume de 3 $\mathrm{m}^{3}$, portanto:

Volume $=$ Qnte de caçambas $*$ volume unitário

Volume $=77 * 3=231 \mathrm{~m}^{3}$

Considerando que a massa unitária do município de Bebedouro é de 0,85 ton $/ \mathrm{m}^{3}$ obtida a partir da qualificação em seu item 4.2, temos:

$231 \mathrm{~m}^{3} * 0,85 \frac{\text { ton }}{\mathrm{m}^{3}}=196,35$ ton ou seja $196.350 \mathrm{Kg}$

Portanto, temos que a taxa de geração de RCC para as cinco obras em análise foi: 
Taxa de geração de RCC $\left(\frac{K g}{m^{2}}\right)=\frac{\text { Massa de entulho }}{\text { Área total das obras }}$

Taxa de geração de RCC $\left(\frac{\mathrm{Kg}}{\mathrm{m}^{2}}\right)=\frac{196.350}{1255,52}$

Taxa de geração de $\operatorname{RCC}\left(\frac{\mathrm{Kg}}{\mathrm{m}^{2}}\right)=156,39 \frac{\mathrm{Kg}}{\mathrm{m}^{2}}$

Aplicando a equação da taxa de geração de RCC pelos parâmetros das áreas licenciadas nos anos de 2017 e 2018, obteve-se a média anual, mensal e diária do RCC do município. A tabela 3 apresenta os resultados obtidos das estimativas da geração do RCC dentro do período de estudo. Assim, pôde-se obter o indicador de geração, sendo de 12.038,47 ton/ano, considerando o mês com 24 dias e supondo o sábado como meio período de trabalho, resultando na média de geração diária dos resíduos de 41,80 ton/dia.

Tabela 3 - Estimativa de geração de RCC por áreas licenciadas

\begin{tabular}{cccc}
\hline & \multicolumn{3}{c}{ Município de Bebedouro SP } \\
\cline { 2 - 4 } & $\mathbf{2 0 1 7}$ & $\mathbf{2 0 1 8}$ & Média \\
\cline { 2 - 4 } Áreas licenciadas $\left(\mathrm{m}^{2}\right)$ & $74.873,31$ & $79.081,17$ & $76.977,24$ \\
Taxa de geração RCC $\left(\mathrm{kg} / \mathrm{m}^{2}\right)$ & 156,39 & 156,39 & 156,39 \\
Geração de RCC (ton/mês) & 975,79 & $1.030,63$ & $1.003,21$ \\
Geração de RCC (ton/ano) & $11.709,44$ & $12.367,5$ & $12.038,47$ \\
\hline Geração de RCC (ton/dia) & $\mathbf{4 0 , 6 6}$ & $\mathbf{4 2 , 9 4}$ & $\mathbf{4 1 , 8 0}$ \\
\hline
\end{tabular}

\subsection{Qualificação dos RCC no munícipio de Bebedouro - SP}

A qualificação dos resíduos foi realizada em parceria com a empresa Bebedouro Caçambas, a qual possui um aterro específico para o descarte das caçambas de entulho recolhidos das obras. Para esta análise foram selecionadas três caçambas de diferentes locais da cidade, com capacidade a máxima de $3 \mathrm{~m}^{3}$ de volume cada.

De cada caçamba foram recolhidas cinco amostras de 18 litros cada, retiradas de vários pontos, para abranger todo o espaço físico da caçamba. Após esse procedimento, os materiais foram separados, limpos e pesados.

A Tabela 4 apresenta todos os dados obtidos nesse procedimento, como os materiais encontrados além de suas massas individuais. 
Tabela 4 - Massas dos materiais encontrados entre os RCC

\begin{tabular}{|c|c|c|c|c|}
\hline \multirow[t]{2}{*}{ Materiais } & \multicolumn{4}{|c|}{ Massa dos materiais no aterro de Bebedouro SP (Kg) } \\
\hline & $\begin{array}{l}\text { Caçamba } 1 \\
\text { (90 Litros) }\end{array}$ & $\begin{array}{c}\text { Caçamba } 2 \\
\text { (90 Litros) }\end{array}$ & $\begin{array}{c}\text { Caçamba } 3 \\
\text { (90 Litros) }\end{array}$ & $\begin{array}{c}\text { Total } \\
\text { (270 Litros) }\end{array}$ \\
\hline Areia/Solo & 5,0 & 0,1 & 0,1 & 5,2 \\
\hline Argamassa/Reboco & 12,5 & - & 59,5 & 72,0 \\
\hline Cerâmica & 38,3 & 5,0 & 24,1 & 67,4 \\
\hline Concreto & - & 64,3 & 9,0 & 73,3 \\
\hline Gesso & 2,5 & - & - & 2,5 \\
\hline Metais & - & 2,0 & 2,0 & 4,0 \\
\hline Madeira & - & 1,5 & - & 1,5 \\
\hline Pedra & 2,8 & - & - & 2,8 \\
\hline Plástico & 0,1 & 0,8 & - & 0,9 \\
\hline Papel & 0,2 & 0,1 & - & 0,3 \\
\hline Total & 61,4 & 73,8 & 94,7 & 229,9 \\
\hline
\end{tabular}

Fonte: Próprio Autor.

Destaca-se que as amostras colhidas durante o processo foram de diferentes pontos da caçamba, assim como chegaram. Os materiais possuíam vazios, então, através da equação em que relaciona a massa e o volume das amostras coletadas no município de Bebedouro, resultase sua massa unitária.

$$
\begin{aligned}
\text { Massa unitária } & =\frac{\text { massa }}{\text { volume das amostras }} \\
\text { Massa unitária } & =\frac{229,90}{270} \\
\text { Massa unitária } & =0,85 \frac{\mathrm{Kg}}{\mathrm{L}} \text { ou seja } 0,85 \frac{\text { ton }}{\mathrm{m}^{3}}
\end{aligned}
$$

Com isso, a massa unitária dos RCC provenientes dessa investigação é de $0,85 \mathrm{~kg} / \mathrm{L}$ ou 0,85 ton $/ \mathrm{m}^{3}$.

Após encontrada a massa unitária do município de Bebedouro SP, ela foi utilizada nos cálculos para haver uma maior realidade dos resultados e visando a geração dos resíduos de construção. Com isso, foi determinada a composição dos RCC, tendo em maior volume encontrado o concreto, com $31,88 \%$, e em seguida a argamassa/reboco, com $31,32 \%$. O Gráfico 1 apresenta os percentuais de todos os materiais encontrados nos RCC analisados. 


\section{Gráfico 1 - Composição percentual de RCC no município de Bebedouro - SP}

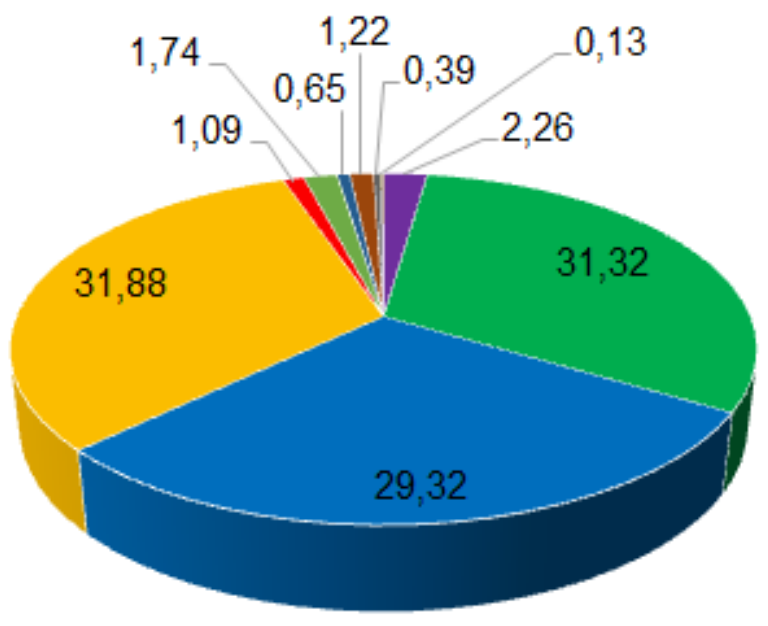

- Areia/Solo

- Argamassa/Reboco

- Cêramica

= Concreto

- Gesso

- Metais

- Madeira

- Pedra

- Plástico

- Papel

Fonte: Próprio Autor.

Analisando o gráfico 1, percebe-se a grande quantidade de resíduos Classe A presentes na composição dos resíduos do município, com predominância da fração mineral. Essa característica mostra o grande potencial de reciclagem para o RCC gerado no município. Além disso, observa-se que $94,78 \%$ do total caracterizado são compostos de concreto, argamassa, solo, cerâmica, gesso, ou seja, materiais potencialmente recicláveis sob a forma de agregados.

\section{CONCLUSÃO}

O estudo dos RCC no município de Bebedouro - SP permitiu o melhor entendimento e também a análise dos resíduos. Revelou ainda a existência de duas áreas de disposição final dos RCC. O resíduo com maior volume encontrado foi o de concreto $(31,88 \%)$, em seguida a argamassa/reboco (31,32\%). Esses resíduos pertencem à classe A, que de acordo com a Resolução CONAMA n ${ }^{\circ}$ 307/02, pode resultar em agregados e ser reutilizado na construção civil.

O município possui uma média diária de geração de resíduos de construção civil de 41,80 toneladas. Tendo em vista a geração de RCC é imprescindível a implantação de um sistema de gestão, afim de que seja superado a degradação do meio ambiente a utilização descontrolada de recursos naturais, dando uma destinação correta para esse resíduo. 


\section{REFERÊNCIAS}

ALVES, T. E. R.; SANTOS, M. do S. F. A gestão de resíduos da construção civil em Teresina - Piauí. 2018. 13 f. Dissertação (Mestrado) - Curso de Engenharia de Produção, Universidade Federal do Piauí - Ufpi, Piauí, 2018.

ASSOCIAÇÃO BRASILEIRA DE NORMAS TÉCNICAS. NBR 15112: Resíduos da construção civil e resíduos volumosos - Áreas de transbordo e triagem - Diretrizes para projeto, implantação e operação. Rio de Janeiro: ABNT, 2004, 7 p.

BARROS, M. V.; SOUZA, J. T. de. Plano de gerenciamento de resíduos sólidos da construção civil: Um panorama de análise a partir da Resolução 307 do

CONAMA. 2017. 15 f. Universidade Tecnológica Federal do Paraná, Ponta Grossa Pr, 2017.

BRASIL, Lei $N^{\circ} 12.305$ de 02 de agosto de 2010 - Política Nacional de Resíduos Sólidos (PNRS).

BRASIL. Ministério do Meio Ambiente. Conselho Nacional do Meio Ambiente - CONAMA. Resolução CONAMA n. 307. Estabelece Diretrizes, Critérios e Procedimentos para a Gestão dos Resíduos da Construção Civil. Brasília, DF, n. 136, 17 de julho de 2002.

GEOGRÁFOS, Google. Localização de Bebedouro - SP. 2019. Disponível em:< https://www.geografos.com.br/cidades-sao-paulo/bebedouro.php>. Acesso em: 02 out. 2019.

INSTITUTO BRASILEIRO DE GEOGRAFIA E ESTATISTICA (IBGE). Pitangueiras-SP. 2018. Disponível em:< https://cidades.ibge.gov.br/brasil/sp/bebedouro/panorama>. Acesso em: 10 abr. 2019.

LEITE, I. C. de A.; DAMASCENO, J. L. C.; REIS, A. M. dos; ALVIM, M. Gestão de resíduos na construção civil: Um estudo em Belo Horizonte e região metropolitana. 2017. 17 f. TCC (Graduação) - Curso de Engenharia Civil, Centro Universitário Izabela hendrix., Belo Horizonte Mg, 2017.

MARQUES NETO, J. da C. Estudo da gestão municipal dos resíduos de construção e demolição na bacia hidrográfica do Turvo Grande (UGRHI-15). 2009. 669 f. Tese (Doutorado) - Curso de Engenharia Civil, Escola de Engenharia de São Carlos da Universidade de São Paulo, São Carlos Sp, 2009.

MARQUES NETO, J. da C. Gestão dos resíduos de construção e demolição no Brasil. 1ed., 162p, São Carlos: Editora RiMa, (2005).

MARQUES NETO, J. da C.; SCHALCH, V. Gestão dos resíduos de construção e demolição: Estudo da situação no município de São Carlos-SP, Brasil. 2010. 10 f. Dissertação (Mestrado) - Curso de Engenharia Civil, Universidade Federal de São Carlos, São Carlos - Sp, 2010.

MENDES, C. A. B.; GIACCOM, R. B. M. Avaliação de parâmetros na estimativa da geração de resíduos sólidos urbanos. Revista Brasileira de Planejamento e Desenvolvimento, Vol.7(3), 2018. 
NASCIMENTO, J. M. do. A importância da compatibilização de projetos como fator de redução de custos na construção civil. Revista Especialize On-line IPOG, v. 1, p.1-11, 2014.

OLIVEIRA, E. G. de; MENDES, O. Gerenciamento de resíduos da construção civil e demolição: Estudo de caso da resolução 307 do Conama. 2018. 14 f. Dissertação (Mestrado) - Curso de Engenharia Ambiental, Universidade Católica de Goiás, Goiânia, 2018.

SHINGO, S. O sistema Toyota de produção, 2a ed. Bookman, São Paulo, 1996.

SILVA, O. H. da; UMADA, M. K.; POLASTRI, P.; NETO, G. de A.; ANGELIS, B. L. D. de; MIOTTO, J. L. Etapas do gerenciamento de resíduos da construção civil. $2015.10 \mathrm{f}$. Universidade Estadual de Maringá, Maringá Pr, 2015.

YEHEYIS, M.; HEWAGE, K.; ALAM, M. S.; ESKICIOGLU, C.; SADIQ, R. An overview of construction and demolition waste management in Canada: a lifecycle analysis approach to sustainability. Clean Technologies and Environmental Policy. n. 15, 2013. 